\title{
Circumstances leading to injurious falls in older men and women in the Netherlands
}

Nicole DA Boyé ${ }^{1,2}$, Francesco US Mattace-Raso ${ }^{1}$, Nathalie Van der Velde ${ }^{1,5}$, Esther MM Van Lieshout $^{2}$, Oscar J De Vries ${ }^{5}$, Klaas A Hartholt ${ }^{1,2}$, Albert JH Kerver ${ }^{6}$, Milko MM Bruijninckx ${ }^{7}$, Tischa JM Van der Cammen ${ }^{1}$, Peter Patka ${ }^{3}$ and, Ed F Van Beeck ${ }^{4}$; IMPROveFALL trial collaborators.

${ }^{1}$ Section of Geriatric Medicine, Department of Internal Medicine, ${ }^{2}$ Department of SurgeryTraumatology, ${ }^{3}$ Department of Accident \& Emergency Medicine, and ${ }^{4}$ Department of Public Health, Erasmus MC, University Medical Center Rotterdam, Rotterdam, The Netherlands. ${ }^{5}$ Department of Internal Medicine, VU University Medical Center, Amsterdam, The Netherlands. ${ }^{6}$ Department of Surgery, Sint Franciscus Gasthuis, Rotterdam, The Netherlands, ${ }^{7}$ Department of Surgery, IJsselland Hospital, Capelle aan den IJssel, The Netherlands.

\section{Corresponding author}

Nicole DA Boyé

Erasmus MC, University Medical Center Rotterdam

PO Box 2040, 3000 CA Rotterdam

The Netherlands

Phone: +31 107035979

Fax: +31 107034768

E-mail: n.boye@erasmusmc.nl

IMPROveFALL trial collaborators

Erasmus MC University Medical Center, Rotterdam 
Van der Cammen TJM, Patka P, Van Beeck EF, Van der Velde N, Van Lieshout EMM,

Polinder S, Mattace Raso FUS, Hartholt KA, Boyé NDA, Van der Weel - Schoemaker APF, Van der Velden - Macauley EN

VU University Medical Center, Amsterdam

Lips P, De Vries OJ, Welman JJ, Verburg A

Sint Franciscus Gasthuis, Rotterdam

Kerver AJH

IJsselland Hospital, Capelle aan den IJssel

Bruijninckx MMM

Reinier de Graaf Groep, Delft

De Vries MR

Havenziekenhuis, Rotterdam

Ziere G 


\section{Funding}

This work was supported by a research grant from the Netherlands Organization for Health Research and Development (ZonMw) [grant number 170.885.607].

\section{Trial Registration}

Netherlands Trial Register NTR1593.

\section{Conflict of Interest Statement}

The authors declare no conflict of interest.

Word count: 2549

\section{Author contributions}

NvdV, EvL, KH, TvdC, PP, and EvB designed the study, obtained funding and recruited participating centres. NB, FMR, NvdV, KH, OdV, TvdC, AK, and MB supervised conduct of trial, screening of records, and collected data. NB, FMR, EvL, and EvB analyzed and interpreted data. NB drafted the manuscript, and all authors contributed substantially to its revision. All authors approved the final version of the manuscript. 


\section{ABSTRACT}

Background: Fall-induced injuries in persons aged 65 years and older are a major public health problem. Data regarding circumstances leading to specific injuries, such as traumatic brain injury (TBI) and hip fractures in older adults are scarce.

Objective: To investigate the activity distributions leading to indoor and outdoor falls requiring an Emergency Department (ED) visit, and those resulting in TBIs and hip fractures. Participants: 5880 older adults who visited the ED due to a fall.

Methods: Data is descriptive and stratified by age and gender.

Results: Two-thirds of all falls occurred indoors. However, there were higher proportions of outdoor falls at ages 65-79 years (48\%). Walking up or down stairs (51\%) and housekeeping (17\%) were the most common indoor activities leading to a TBIs. Walking (42\%) and sitting or standing (16\%) were the most common indoor activities leading to a hip fracture. The most common outdoor activities were walking (61\% for TBIs and 57\% for hip fractures) and cycling (10\% for TBIs and 24\% for hip fractures).

Conclusion: In the present study we found that the indoor activities distribution leading to TBIs and hip fractures differed. Notably, about half of the traumatic brain injuries and hip fractures in men and women aged 65-79 years occurred outdoors. This study provides new insights into patterns leading to injurious falls by age, gender and injury type, and may guide the targeting of falls prevention at specific activities and risk groups, including highly functional older men and women. 


\section{INTRODUCTION}

Falls affect approximately a third of the population aged 65 years and older, and are associated with major adverse consequences such as disability, loss of quality of life, institutionalization, and high morbidity and mortality rates ${ }^{1-8}$. Furthermore, falls place a substantial burden on healthcare systems due to the large amount of visits to emergency departments, hospital admissions, admissions to long-term care and rehabilitation facilities, and related healthcare costs ${ }^{3,4,7,9-11}$ making falls prevention a public health priority ${ }^{12,13}$.

The most common injuries due to falls in the population aged 65 years and older in the Netherlands are superficial injuries, hip fractures, upper extremity fractures, and traumatic brain injury $(\mathrm{TBI})^{10}$. Approximately $30 \%$ of people with a hip fracture will die within a year, and many more will experience significant functional loss ${ }^{2}$. Similarly, TBI is associated with serious consequences. Falls cause $61 \%$ of TBIs among persons aged 65 years and older in the United States ${ }^{14}$. Furthermore, recent studies in the United States ${ }^{14}$, the Netherlands ${ }^{15}$, and Finland ${ }^{16}$ showed an increase in fall-related TBIs.

An important yet overlooked aspect regarding falls in the elderly is the paucity of evidence regarding patterns in the circumstances leading to injurious falls. Falls are the most important cause of TBIs and hip fractures in older adults, thus these patterns are valuable because they could highlight subgroups that may benefit from targeted falls prevention strategies ${ }^{2,15,17}$. However, data on circumstances leading to major consequences of falls in older adults, such as hip fractures and TBIs are scarce; and the number of events in the available studies is relatively low ${ }^{18-21}$.

In this study, we investigated the indoor and outdoor activities leading to injurious falls in a large number of older men and women who visited the Emergency Department (ED) after experiencing a fall. 


\section{METHODS}

\section{Study population}

For the present study, screening data were extracted from the IMPROveFALL study ${ }^{22}$. The IMPROveFALL study is a randomized multicenter trial investigating the effect of withdrawal of fall-risk increasing drugs versus ‘care as usual' on reducing falls in community-dwelling older men and women. Patients meeting the following criteria were screened for potential enrolment in the IMPROveFALL study: aged 65 years or older, visited the ED due to a fall. A fall was defined as coming to rest unintentionally on the ground or a lower level with or without losing consciousness, but not induced by acute medical conditions, e.g. stroke, or exogenous factors such as a traffic accident ${ }^{23}$. All patients meeting the screening criteria were included in the current study. Screening was performed at two academic and five regional hospitals in the Netherlands, all located in highly urbanized areas. Screening started in October 2008 and was completed in October 2011. The local Medical Research Ethics Committees at all participating sites approved the study.

\section{Data collection}

Data regarding age, gender, dwelling, date of ED visit, location of fall, activity during fall, and injuries sustained were collected from ED records. Records were made by ED personnel, were free-form, and paper or electronic depending on the hospital. Records were collected and managed by the research nurse and research physician. ED personnel were not aware of specific data being collected from records, therefore, there was a fair amount of missing data. Regarding the location of the fall, $27 \%$ of the data were missing; and regarding activity prior to the fall, $34 \%$ of the data was missing. Data regarding hospital stay and hospital mortality were not collected. 
Age was categorised as 65 to 79 years old or 80 years and older. Dwelling was categorised as community-dwelling or living in a care facility (assisted living facility or nursing home). Location at time of fall was categorised as indoors or outdoors. Activity at time of fall was categorised as walking, sitting or standing, walking up or down stairs, lavatory visit, sports and recreation, out of bed, housekeeping, cycling, or other. Season during which fall occurred was categorised as winter (December, January and February), spring (March. April and May), summer (June, July and August), and autumn (September, October and November). Injuries were defined by the International Classification of Diseases $10^{\text {th }}$ revision (ICD-10) ${ }^{24}$ and categorised as superficial injury, open wound, head injuries (i.e., superficial injury, open wound, skull/facial fracture, and TBI), and fractures (i.e., spine, rib, shoulder and upper arm, elbow and forearm, wrist and hand, pelvis, hip, knee and lower leg, or ankle and foot). Activity distributions leading to indoor and outdoor falls were described separately for all falls, and for the two major fall-related injuries, i.e. TBIs and hip fractures. 


\section{RESULTS}

In total data of 5880 fall-related ED visits of persons aged 65 years and older were included in this study. The mean age was 80 years with a standard deviation of 8 , and the study population consisted of 1824 (31\%) men and 4056 (69\%) women.

The overall gender and age specific circumstances surrounding a fall are shown in table 1. Data concerning dwelling was obtained from 5489 patients. Most patients were community-dwelling ( $n=4734,86 \%$ ), with $95 \%$ of both men and women aged 65-79 years, and $83 \%$ of the men and $75 \%$ of women aged $\geq 80$ years being community-dwelling, the remaining were residing in a care facility. Data concerning location of the fall were obtained from 4279 patients. Most falls occurred indoors ( $n=2773,65 \%)$. However, this differed between the age and gender categories; there were higher proportions of outdoor falls at ages $65-79$ years (48\%), and overall $41 \%$ of the men fell outdoors. Data concerning activity were obtained from 3871 participants. Overall, the most common activity at time of the fall was walking ( $n=1898,49 \%)$. Other common activities were walking up or down stairs $(n=409$, 11\%) and sitting / standing ( $\mathrm{n}=371,10 \%)$. Data concerning the season during which the fall occurred was obtained from all 5880 patients. Overall most falls occurred during summer ( $n=1802,31 \%$ ), $28 \%$ of men and 32\% of women fell during summer. The least amount of falls occurred during autumn (22\%) for men, and winter (21\%) for women.

Of the ED records with missing data regarding either the location or activity at time of the fall, the mean age was 81 years with a standard deviation of 8 , and the population consisted of 687 (27\%) men, and 1822 (73\%) women. Furthermore, 1819 (81\%) were community-dwelling, and 421 (19\%) resided in a care-facility.

The age and gender specific injuries following a fall are shown in table 2. Data concerning injury were collected from all 5880 patients. Falls caused superficial injury in 
1951 patients (33\%), open wounds in 461 (8\%), TBIs in 254 (4\%) and fractures in 2700 (46\%) of the population. The most common fracture was a hip fracture (n=883, 15\%).

\section{All injurious falls}

The location and activity surrounding a fall requiring an ED visit was obtained from 3371 records and are shown in figure 1 . The overall most common indoor activities were walking $(\mathrm{n}=658,34 \%)$ and walking up or down stairs ( $\mathrm{n}=322,17 \%)$ [Figure $1 \mathrm{~A}, \mathrm{~B}$ ]. The overall most common outdoor activities were walking ( $n=946,66 \%)$ and cycling $(n=200,14 \%)$ [Figure 1 C, D].

\section{Traumatic brain injury}

Overall, 254 falls resulted in a TBI. The location and activity surrounding a fall leading to a TBI was obtained from 176 records and are shown in figure 2. Falls resulting in TBIs had a similar indoor $(n=92,52 \%)$ and outdoor $(n=84,48 \%)$ prevalence. The most common indoor activities were walking up or down stairs $(n=47,51 \%)$ and housekeeping $(n=16,17 \%)$ [Figure 2 A, B]. The most common outdoor activities were walking $(n=51,61 \%)$ and cycling $(n=8$, 10\%) [Figure $2 \mathrm{C}, \mathrm{D}]$.

\section{Hip fractures}

Overall, 883 falls resulted in a hip fracture. The location and activity surrounding a fall leading to a hip fracture was obtained from 468 records and are shown in figure 3. A fall resulting in a hip fracture most commonly occurred indoors ( $n=341,73 \%)$ except for the men aged 65-79 years, in whom hip fractures most commonly occurred outdoors $(n=33,54 \%)$. The most common indoor activities were walking $(n=144,42 \%)$ and sitting or standing $(n=55$, 
16\%) [Figure $3 \mathrm{~A}, \mathrm{~B}$ ]. The most common outdoor activities were walking ( $\mathrm{n}=72,57 \%)$ and cycling ( $\mathrm{n}=30,24 \%)$ [Figure $3 \mathrm{C}, \mathrm{D}]$.

\section{Falls by season}

The season, location and activity surrounding a fall requiring an ED visit was obtained from 3371 records and are shown in supplementary figure $\mathrm{X}$. The most common indoor activities surrounding a fall during winter were walking $(\mathrm{n}=123,33 \%)$ and walking up or down stairs ( $n=65,18 \%$ ). The most common outdoor activities surrounding a fall during winter were walking ( $n=300,77 \%)$ and cycling $(n=37,10 \%)$. The most common indoor activities during spring were walking (n=160,33\%) and walking up or down stairs $(n=79,16 \%)$ and housekeeping ( $\mathrm{n}=79,16 \%)$. The most common outdoor activities during spring were walking ( $n=224,64 \%)$ and cycling $(n=44,13 \%)$. The most common indoor activities during summer were walking ( $n=192,33 \%)$ and walking up or down stairs $(n=100,17 \%)$. The most common outdoor activities during summer were walking $(n=227,59 \%)$ and cycling $(n=84,22 \%)$. The most common indoor activities during autumn were walking ( $\mathrm{n}=183,36 \%)$ and housekeeping ( $n=87,17 \%)$. The most common outdoor activities during autumn were walking $(n=195$, $65 \%)$ and cycling ( $\mathrm{n}=35,12 \%)$. 


\section{DISCUSSION}

In this study two-thirds of all falls occurred indoors. However, this differed between the age and gender categories, with higher proportions of outdoor falls at ages 65-79 years and among men. The overall most common indoor activities leading to injurious falls were walking and walking up or down stairs. The overall most common outdoor activities were walking and cycling. We found that the indoor activities leading to major injuries, i.e. TBIs and hip fractures differed. Walking up or down stairs and housekeeping were the most common activities leading to a TBIs whereas walking and sitting / standing were the most common activities leading to a hip fracture. Notably, about half of the traumatic brain injuries and hip fractures in men and women aged 65-79 years occurred outdoors. The most common outdoor activities leading to both injuries were walking and cycling. To our knowledge this is the largest study investigating patterns leading to fall-related TBIs and hip fractures in community dwelling older adults.

Falls are the leading cause of TBIs and hip fractures in the elderly population ${ }^{4,15,17}$. Falls cause $61 \%$ of traumatic brain injuries in persons aged 65 years and older in the US ${ }^{17}$, and recent studies in the US, the Netherlands, and Finland showed an increase in fall-related TBIs ${ }^{15-17}$. About $30 \%$ of people with a hip fracture will die in the following year, and many more will experience significant functional loss ${ }^{2}$. Furthermore, TBIs and hip fractures contribute considerably to healthcare costs ${ }^{4}$. Therefore, interventions targeted toward this group have the potential to be very (cost-) effective. The two most common indoor activities leading to a TBI were walking up or down stairs and housekeeping. Furthermore, about half of the hip fractures in men and women aged 65-79 years occurred outdoors, and approximately a third of those while cycling. These all suggest high activity levels. Up to now, little to no special attention has been paid to outdoor activities such as cycling and 
'higher level' activities such as housekeeping. Few have incorporated strategies for falls prevention derived from these specific circumstances. Partly, this can be accomplished by education of the risk groups. Healthy and highly functional older adults may be unaware that their higher activity levels may increase their risk for falling and subsequent injuries ${ }^{25}$. Another possibility is the elimination of outdoor environmental hazards involving sidewalks, curbs, and streets, such as by promptly repairing uneven surfaces, removing debris, and painting curbs ${ }^{26,27}$. Furthermore, promotion of measures which can reduce the severity of injuries following a fall, such as bicycle helmets, should also be considered ${ }^{28}$.

It should be noted that in the Netherlands about $27 \%$ of all travel is done by bicycle. As a consequence, the data presented is more relevant in countries where cycling is common. Other western countries where cycling is a common mode of transportation are, Denmark (18\% of all travel), Finland (11\%), Germany (10\%), and Sweden $(10 \%)^{29}$. Whereas in the United States and the United Kingdom only $1 \%$ of all trips are by bicycle ${ }^{29}$.

In this study, most falls occurred during summer (31\%), and the least during winter (21\%), this differed from other studies ${ }^{30-32}$, where most falls occurred during winter, and a recent study which showed seasons had no effect on fall rates ${ }^{33}$. Possibly more falls occurred during summer due to people being more active during the warm summer months compared to winter. Furthermore, snow and ice might not have been a major factor as in previous studies, due to the relatively mild winters in urban areas of the Netherlands. The most common indoor and outdoor activities leading to a fall during the four seasons were similar, noteworthy were the rates for walking outdoors during winter (77\%), and cycling outdoors during summer (22\%).

Various studies have investigated circumstances surrounding falls in older adults ${ }^{25-}$ 27,34-45. However, these studies investigated falls in general and not falls resulting in major injuries. Furthermore, the study population of two of the latest studies consisted of older 
adults dwelling in care-facilities, an older and frailer population, in which the majority of falls occurred indoors ${ }^{33,44}$. Two recent studies suggest that different types of fall-risk assessment are needed for indoor and outdoor fallers. And propose that, prevention recommendations would be more effective if targeted differently for frail, inactive older people at risk for indoor falls and relatively active healthy older people at risk for outdoor falls ${ }^{41,42}$.

The following limitations should be acknowledged when interpreting the results of this study. First, all data were gathered from ED records, we did not include persons who visited a general practitioner or persons who did not seek medical attention after a fall. Therefore, this is not a report on circumstances surrounding all falls in older adults. Nevertheless, our objective was to investigate falls resulting in injuries, not falls in general. Second, the Netherlands has more bicyclists and pedestrians that most Western countries, reducing the generalizability. Third, part of the data regarding either the location or the activity at time of fall was missing from ED records, which may have introduced bias into the results. Overall, the patient characteristics of the missing records differed slightly regarding age, gender and dwelling. However, the most significant difference was the hospital where data was gathered, possibly due to differences in recordkeeping methods. Furthermore, these results are otherwise scarce and remain valuable, especially for the subgroup of older men and women with 'higher level' activities. Strengths of this study include the study population size, and that data was collected from ED records and thus included detailed information concerning injuries sustained.

In conclusion, in the present study we found distinct fall and injury patterns, i.e. where and how, leading to TBIs and hip fractures in older men and women. Notably, about half of the traumatic brain injuries and hip fractures in men and women aged 65-79 years occurred outdoors. This study provides new insights into patterns leading to injurious falls by age, 
gender and injury type, and may guide the targeting of falls prevention at specific activities and risk groups, including highly functional older men and women. 


\section{ACKNOWLEDGEMENTS}

\section{Conflict of Interest Statement}

The authors declare no conflict of interest. 


\section{REFERENCES}

1. Boonen S, Autier P, Barette M, Vanderschueren D, Lips P, Haentjens P. Functional outcome and quality of life following hip fracture in elderly women: a prospective controlled study. Osteoporos Int. Feb 2004;15(2):87-94.

2. Brauer CA, Coca-Perraillon M, Cutler DM, Rosen AB. Incidence and mortality of hip fractures in the United States. Jama. Oct 14 2009;302(14):1573-1579.

3. Close JC, Lord SR, Antonova EJ, Martin M, Lensberg B, Taylor M, et al. Older people presenting to the emergency department after a fall: a population with substantial recurrent healthcare use. Emerg Med J. Oct 12011.

4. Hartholt KA, van Beeck EF, Polinder S, van der Velde N, van Lieshout EM, Panneman MJ, et al. Societal consequences of falls in the older population: injuries, healthcare costs, and long-term reduced quality of life. J Trauma. Sep 2010;71(3):748753.

5. Kochanek KD, Xu JQ, Murphy SL, al. e. Deaths: Preliminary data for 2009. . Vol National vital statistics reports; vol 59 no 4.: Hyattsville, MD: National Center for Health Statistics. ; 2011.

6. Randell AG, Nguyen TV, Bhalerao N, Silverman SL, Sambrook PN, Eisman JA. Deterioration in quality of life following hip fracture: a prospective study. Osteoporos Int. 2000;11(5):460-466.

7. Stevens JA, Corso PS, Finkelstein EA, Miller TR. The costs of fatal and non-fatal falls among older adults. Inj Prev. Oct 2006;12(5):290-295.

8. Tinetti ME, Baker DI, McAvay G, Claus EB, Garrett P, Gottschalk M, et al. A multifactorial intervention to reduce the risk of falling among elderly people living in the community. N Engl J Med. Sep 29 1994;331(13):821-827. 
9. Greenspan AI, Coronado VG, Mackenzie EJ, Schulman J, Pierce B, Provenzano G. Injury hospitalizations: using the nationwide inpatient sample. J Trauma. Nov 2006;61(5):1234-1243.

10. Hartholt KA, van der Velde N, Looman CW, van Lieshout EMM, Panneman MJ, van Beeck EF, et al. Trends in fall-related hospital admissions in older persons in the Netherlands. Arch Intern Med. May 24 2010;170(10):905-911.

11. Scuffham $P$, Chaplin $S$, Legood R. Incidence and costs of unintentional falls in older people in the United Kingdom. J Epidemiol Community Health. Sep 2003;57(9):740744.

12. AGS/BGS. Summary of the Updated American Geriatrics Society/British Geriatrics Society clinical practice guideline for prevention of falls in older persons. $J$ Am Geriatr Soc. Jan 2010;59(1):148-157.

13. AGS/BGS/AAOS. Guideline for the prevention of falls in older persons. American Geriatrics Society, British Geriatrics Society, and American Academy of Orthopaedic Surgeons Panel on Falls Prevention. J Am Geriatr Soc. May 2001;49(5):664-672.

14. Faul M, Xu, L., Wald, M., and Coronado, V. . Traumatic Brain Injury in the United States: Emergency Department Visits, Hospitalizations and Deaths 2002-2006. . Centers for Disease Control and Prevention, National Center for Injury Prevention and Control: Atlanta. 2010.

15. Hartholt KA, Van Lieshout EMM, Polinder S, Panneman MJ, Van der Cammen TJM, Patka P. Rapid increase in hospitalizations resulting from fall-related traumatic head injury in older adults in The Netherlands 1986-2008. J Neurotrauma. May 2011;28(5):739-744.

16. Kannus P, Niemi S, Parkkari J, Palvanen M, Sievanen H. Alarming rise in fall-induced severe head injuries among elderly people. Injury. Jan 2007;38(1):81-83. 
17. Faul M, Xu L, Wald MM, Coronado VG. Traumatic Brain Injury in the United States: Emergency Department Visits, Hospitalizations and Deaths 2002-2006. In: Centers for Disease Control and Prevention NCfIPaC, ed2010.

18. Abolhassani F, Moayyeri A, Naghavi M, Soltani A, Larijani B, Shalmani HT. Incidence and characteristics of falls leading to hip fracture in Iranian population. Bone. Aug 2006;39(2):408-413.

19. Aharonoff GB, Dennis MG, Elshinawy A, Zuckerman JD, Koval KJ. Circumstances of falls causing hip fractures in the elderly. Clin Orthop Relat Res. Mar 1998(348):1014.

20. Allander E, Gullberg B, Johnell O, Kanis JA, Ranstam J, Elffors L. Circumstances around the fall in a multinational hip fracture risk study: a diverse pattern for prevention. MEDOS Study Group). Mediterranean Osteoporosis Study. Accid Anal Prev. Sep 1998;30(5):607-616.

21. Harvey LA, Close JC. Traumatic brain injury in older adults: characteristics, causes and consequences. Injury. Nov 2012;43(11):1821-1826.

22. Hartholt KA, Boyé NDA, Van der Velde N, Van Lieshout EMM, Polinder S, De Vries OJ, et al. [Cost]effectiveness of withdrawal of fall-risk increasing drugs versus conservative treatment in older fallers: design of a multicenter randomized controlled trial (IMPROveFALL-study). BMC Geriatr. 2011;11:48.

23. KIWG. The prevention of falls in later life. A report of the Kellogg International Work Group on the Prevention of Falls by the Elderly. Dan Med Bull. Apr 1987;34 Suppl $4: 1-24$

24. WHO. ICD-10: International statistical classification of diseases and related health problems 10th Rev. ed.: World Health Organization 2008. 
25. Bath PA, Morgan K. Differential risk factor profiles for indoor and outdoor falls in older people living at home in Nottingham, UK. Eur J Epidemiol. Jan 1999;15(1):6573.

26. Lai PC, Wong WC, Low CT, Wong M, Chan MH. A small-area study of environmental risk assessment of outdoor falls. J Med Syst. Dec 2011;35(6):15431552.

27. Li W, Keegan TH, Sternfeld B, Sidney S, Quesenberry CP, Jr., Kelsey JL. Outdoor falls among middle-aged and older adults: a neglected public health problem. Am J Public Health. Jul 2006;96(7):1192-1200.

28. Macpherson A, Spinks A. Bicycle helmet legislation for the uptake of helmet use and prevention of head injuries. Cochrane Database Syst Rev. 2008(3):CD005401.

29. Pucher J, Buehler J. Making Cycling Irresistible: Lessons from the Netherland, Denmark, and Germany. Transport Reviews. July 2008 2008;28(4):495-528.

30. Berg WP, Alessio HM, Mills EM, Tong C. Circumstances and consequences of falls in independent community-dwelling older adults. Age Ageing. Jul 1997;26(4):261268.

31. Kojima S, Furuna T, Ikeda N, Nakamura M, Sawada Y. Falls among communitydwelling elderly people of Hokkaido, Japan. Geriatr Gerontol Int. Dec 2008;8(4):272277.

32. Nachreiner NM, Findorff MJ, Wyman JF, McCarthy TC. Circumstances and consequences of falls in community-dwelling older women. $J$ Womens Health (Larchmt). Dec 2007;16(10):1437-1446.

33. Rapp K, Becker C, Cameron ID, Konig HH, Buchele G. Epidemiology of falls in residential aged care: analysis of more than 70,000 falls from residents of bavarian nursing homes. J Am Med Dir Assoc. Feb 2012;13(2):187 e181-186. 
34. Ashley MJ, Gryfe CI, Amies A. A longitudinal study of falls in an elderly population II. Some circumstances of falling. Age Ageing. Nov 1977;6(4):211-220.

35. Bergland A, Pettersen AM, Laake K. Falls reported among elderly Norwegians living at home. Physiother Res Int. 1998;3(3):164-174.

36. Bleijlevens MH, Diederiks JP, Hendriks MR, van Haastregt JC, Crebolder HF, van Eijk JT. Relationship between location and activity in injurious falls: an exploratory study. BMC Geriatr. 2010;10:40.

37. Campbell AJ, Borrie MJ, Spears GF, Jackson SL, Brown JS, Fitzgerald JL. Circumstances and consequences of falls experienced by a community population 70 years and over during a prospective study. Age Ageing. Mar 1990;19(2):136-141.

38. Coutinho ES, Bloch KV, Rodrigues LC. Characteristics and circumstances of falls leading to severe fractures in elderly people in Rio de Janeiro, Brazil. Cad Saude Publica. Feb 2009;25(2):455-459.

39. Hill K, Schwarz J, Flicker L, Carroll S. Falls among healthy, community-dwelling, older women: a prospective study of frequency, circumstances, consequences and prediction accuracy. Aust N Z J Public Health. Feb 1999;23(1):41-48.

40. Jensen J, Lundin-Olsson L, Nyberg L, Gustafson Y. Falls among frail older people in residential care. Scand J Public Health. 2002;30(1):54-61.

41. Kelsey JL, Berry SD, Procter-Gray E, Quach L, Nguyen US, Li W, et al. Indoor and outdoor falls in older adults are different: the maintenance of balance, independent living, intellect, and Zest in the Elderly of Boston Study. J Am Geriatr Soc. Nov 2010;58(11):2135-2141.

42. Kelsey JL, Procter-Gray E, Berry SD, Hannan MT, Kiel DP, Lipsitz LA, et al. Reevaluating the implications of recurrent falls in older adults: location changes the inference. J Am Geriatr Soc. Mar 2012;60(3):517-524. 
43. Nevitt MC, Cummings SR, Hudes ES. Risk factors for injurious falls: a prospective study. J Gerontol. Sep 1991;46(5):M164-170.

44. Robinovitch SN, Feldman F, Yang Y, Schonnop R, Leung PM, Sarraf T, et al. Video capture of the circumstances of falls in elderly people residing in long-term care: an observational study. Lancet. Jan 5 2012;381(9860):47-54.

45. Yasumura S, Haga H, Niino N. Circumstances of injurious falls leading to medical care among elderly people living in a rural community. Arch Gerontol Geriatr. SepOct 1996;23(2):95-109. 
Table 1. Circumstances surrounding injurious falls stratified by gender and age

\begin{tabular}{|c|c|c|c|c|c|c|c|}
\hline & \multirow[t]{2}{*}{ Total } & \multicolumn{3}{|c|}{ Men } & \multicolumn{3}{|c|}{ Women } \\
\hline & & $65-79 y$ & $\geq 80 y$ & Total & $65-79 y$ & $\geq 80 y$ & Total \\
\hline & $\mathrm{n}=5880$ & $\mathrm{n}=1095$ & $\mathrm{n}=729$ & $\mathrm{n}=1824$ & $\mathrm{n}=1851$ & $\mathrm{n}=2205$ & $\mathrm{n}=4056$ \\
\hline Dwelling & $\mathrm{n}=5489$ & $\mathrm{n}=1065$ & $\mathrm{n}=673$ & $\mathrm{n}=1738$ & $\mathrm{n}=1753$ & $\mathrm{n}=1998$ & $\mathrm{n}=3751$ \\
\hline Community & $4734(86)$ & 1013 (95) & $561(83)$ & $1574(91)$ & 1663 (95) & $1497(75)$ & $3160(84)$ \\
\hline Care facility & 755 (14) & $52(5)$ & $112(17)$ & $164(9)$ & $90(5)$ & $501(25)$ & $591(16)$ \\
\hline Location & $\mathrm{n}=4279$ & $\mathrm{n}=815$ & $\mathrm{n}=562$ & $\mathrm{n}=1377$ & $n=1306$ & $\mathrm{n}=1596$ & $\mathrm{n}=2902$ \\
\hline Indoor & $2773(65)$ & $428(53)$ & 390 (69) & 818 (59) & $673(52)$ & $1282(80)$ & 1955 (67) \\
\hline Outdoor & $1506(35)$ & 387 (48) & $172(31)$ & $559(41)$ & $633(48)$ & $314(20)$ & 947 (33) \\
\hline Activity & $\mathrm{n}=3871$ & $\mathrm{n}=818$ & $n=472$ & $\mathrm{n}=1290$ & $n=1302$ & $\mathrm{n}=1279$ & $\mathrm{n}=2581$ \\
\hline Walking & $1898(49)$ & 314 (38) & $232(49)$ & $546(42)$ & $690(53)$ & $662(52)$ & $1352(52)$ \\
\hline Sitting \& Standing & $371(10)$ & $63(8)$ & $56(12)$ & $119(9)$ & $90(7)$ & $162(13)$ & $252(10)$ \\
\hline Walking up or down stairs & 409 (11) & $142(17)$ & $45(10)$ & $187(15)$ & $142(11)$ & $80(6)$ & $222(9)$ \\
\hline Lavatory visit & $161(4)$ & $22(3)$ & $21(4)$ & $43(3)$ & $42(3)$ & $76(6)$ & $118(5)$ \\
\hline Sports \& Recreation & $51(1)$ & $21(3)$ & $3(1)$ & $24(2)$ & $20(2)$ & $7(1)$ & $27(1)$ \\
\hline Out of bed & $107(3)$ & $15(2)$ & $18(4)$ & $33(3)$ & $19(2)$ & $55(4)$ & $74(3)$ \\
\hline Housekeeping & $331(9)$ & $85(10)$ & $38(8)$ & $123(10)$ & $88(7)$ & $120(9)$ & $208(8)$ \\
\hline Cycling & $200(5)$ & $74(9)$ & $13(3)$ & $87(7)$ & $88(7)$ & $25(2)$ & $113(4)$ \\
\hline Other & $343(9)$ & $82(10)$ & $46(10)$ & $128(10)$ & $123(9)$ & $92(7)$ & $215(8)$ \\
\hline Season & $\mathrm{n}=5880$ & $\mathrm{n}=1095$ & $\mathrm{n}=729$ & $\mathrm{n}=1824$ & $\mathrm{n}=1851$ & $\mathrm{n}=2205$ & $\mathrm{n}=4056$ \\
\hline Winter & $1258(21)$ & $265(24)$ & $160(22)$ & $425(23)$ & $437(24)$ & $396(18)$ & $833(21)$ \\
\hline Spring & $1472(25)$ & $292(27)$ & $194(27)$ & $486(27)$ & $448(24)$ & $538(24)$ & $986(24)$ \\
\hline Summer & $1802(31)$ & 306 (28) & 201 (28) & 507 (28) & $549(30)$ & 746 (34) & $1295(32)$ \\
\hline Autumn & $1348(23)$ & $232(21)$ & $174(24)$ & $406(22)$ & 417 (23) & 525 (24) & 942 (23) \\
\hline
\end{tabular}

Data are given as number (percentages). 
Table 2. Injuries following a fall stratified by gender and age

\begin{tabular}{|c|c|c|c|c|c|c|c|}
\hline & \multirow[t]{2}{*}{ Total } & \multicolumn{3}{|c|}{ Men } & \multicolumn{3}{|c|}{ Women } \\
\hline & & $65-79 y$ & $\geq 80 y$ & Total & $65-79 y$ & $\geq 80 y$ & Total \\
\hline & $\mathrm{n}=5880$ & $\mathrm{n}=1095$ & $\mathrm{n}=729$ & $\mathrm{n}=1824$ & $\mathrm{n}=1851$ & $\mathrm{n}=2205$ & $\mathrm{n}=4056$ \\
\hline Superficial injury & $1951(33)$ & $385(35)$ & $244(34)$ & $629(35)$ & $603(33)$ & 719 (33) & $1322(33)$ \\
\hline Open wound & $461(8)$ & $103(9)$ & $96(13)$ & $199(11)$ & $109(6)$ & $153(7)$ & $262(7)$ \\
\hline \multicolumn{8}{|l|}{ Injuries to the head } \\
\hline SI head & $629(11)$ & $150(14)$ & $97(13)$ & $247(14)$ & $160(9)$ & $222(10)$ & $382(9)$ \\
\hline Open wound of head & $289(5)$ & $69(6)$ & $74(10)$ & $143(8)$ & $66(4)$ & $79(4)$ & $145(4)$ \\
\hline Skull/facial fracture & $82(1)$ & $19(2)$ & $8(1)$ & $27(2)$ & $26(1)$ & $29(1)$ & $55(1)$ \\
\hline Traumatic brain injury & $254(4)$ & $81(7)$ & $42(6)$ & $123(7)$ & $67(4)$ & $64(3)$ & $131(3)$ \\
\hline \multicolumn{8}{|l|}{ Fractures } \\
\hline All fractures & $2700(46)$ & $349(32)$ & $274(38)$ & $623(34)$ & $929(50)$ & $1148(52)$ & 2077 (51) \\
\hline Spine & $127(2)$ & $24(2)$ & $12(2)$ & $36(2)$ & $37(2)$ & $54(2)$ & $91(2)$ \\
\hline Rib & $92(2)$ & $35(3)$ & $14(2)$ & $49(3)$ & $13(1)$ & $30(1)$ & $43(1)$ \\
\hline Shoulder and upper arm & $400(7)$ & $53(5)$ & $38(5)$ & $91(5)$ & $160(9)$ & $149(7)$ & 309 (8) \\
\hline Elbow and forearm & 517 (9) & $57(5)$ & $19(3)$ & $76(4)$ & $248(13)$ & $193(9)$ & $441(11)$ \\
\hline Wrist and hand & $289(5)$ & $42(4)$ & $20(3)$ & $62(3)$ & $139(8)$ & $88(4)$ & $227(6)$ \\
\hline Pelvis & $133(2)$ & $9(1)$ & $10(1)$ & $19(1)$ & $33(2)$ & $81(4)$ & $114(3)$ \\
\hline Hip & $883(15)$ & $86(8)$ & $143(20)$ & 229 (13) & $170(9)$ & $484(22)$ & $654(16)$ \\
\hline Knee and lower leg & $106(2)$ & $15(1)$ & $9(1)$ & $24(1)$ & $43(2)$ & $39(2)$ & $82(2)$ \\
\hline Ankle and foot & $174(3)$ & $22(2)$ & $9(1)$ & $31(2)$ & $93(5)$ & $50(2)$ & $143(4)$ \\
\hline
\end{tabular}

Data are given as number (percentages). SI: superficial injury. 


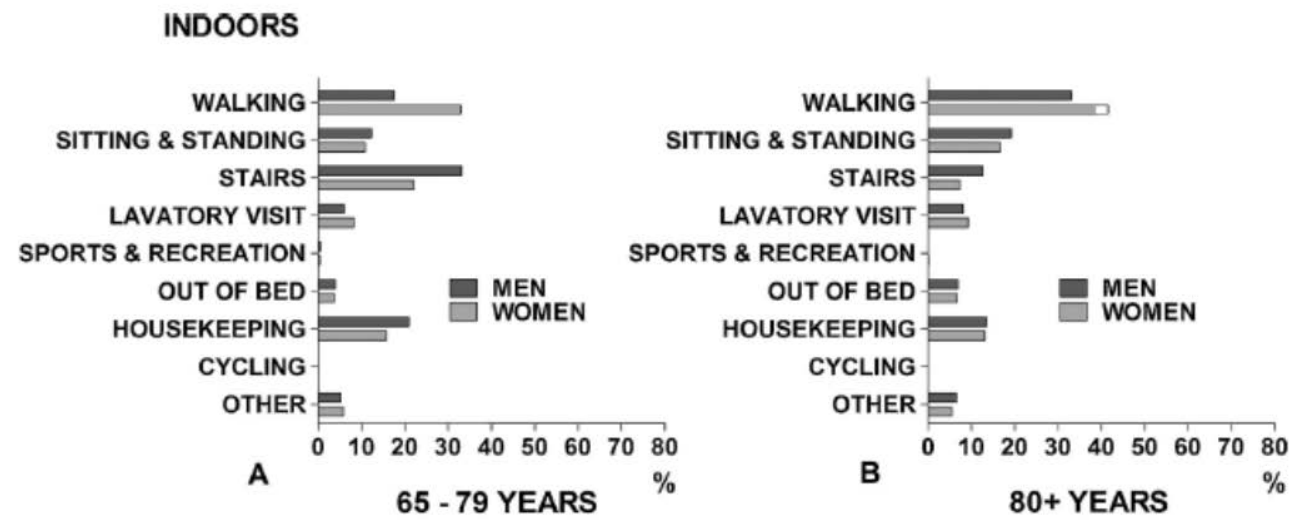

OUTDOORS

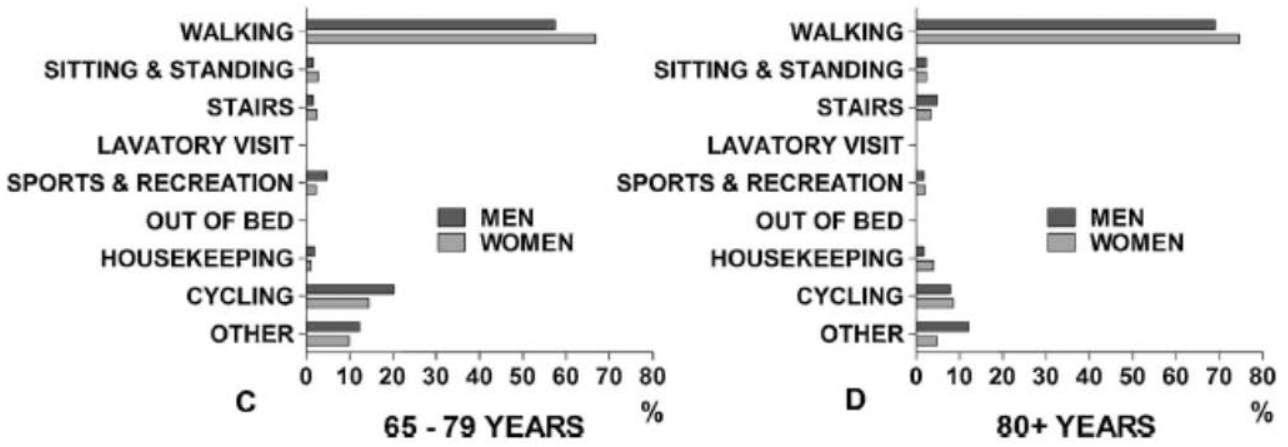

Fig. 1. Circumstances leading to all injurious falls, stratified by age and gender. Indoor ( $A$ and $B$ ) and outdoor (C and D) activities leading to a fall requiring an emergency department visit, stratified by the age categories 65-79 years ( $A$ and $C$ ) and $80+$ years ( $B$ and $D)$. Data are shown in percentages. 


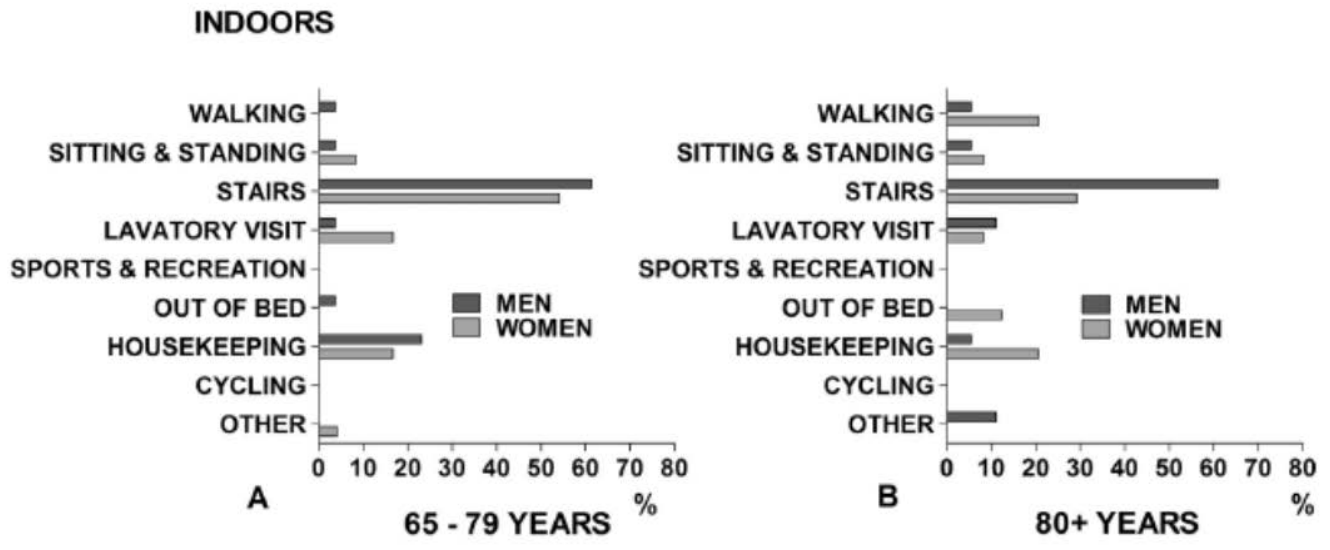

\section{OUTDOORS}
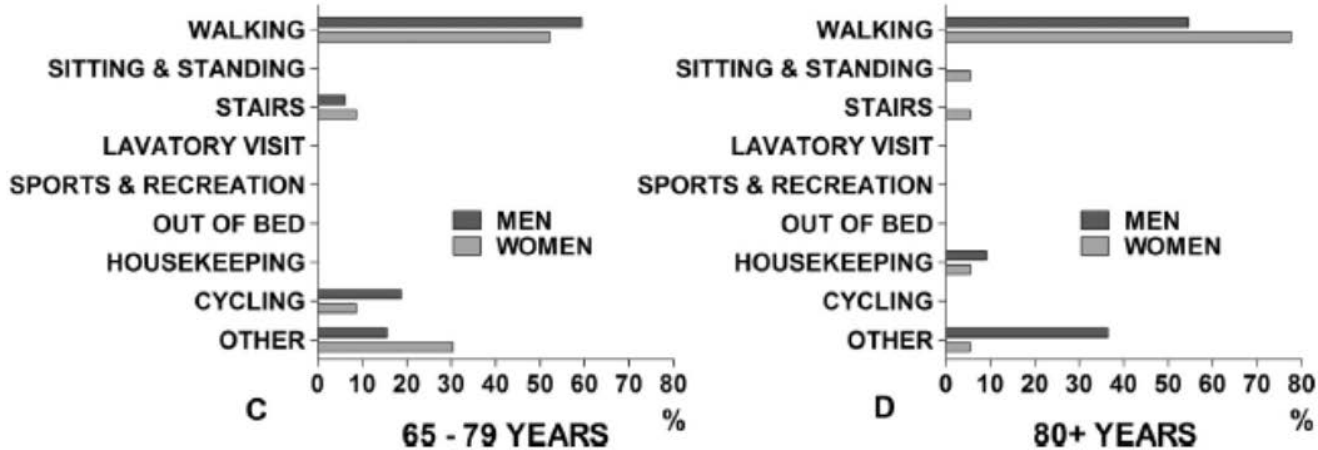

Fig. 2. Circumstances sur rounding falls leading to traumatic brain injury, stratified by age and gender. Indoor ( $A$ and $B$ ) and ou tdoor ( $C$ and $D)$ activities leading to a traumatic brain injury, stratified by the age categories $65-79$ years $(A$ and $C$ ) and $80+$ years (B and D). Data are shown in percentages. 


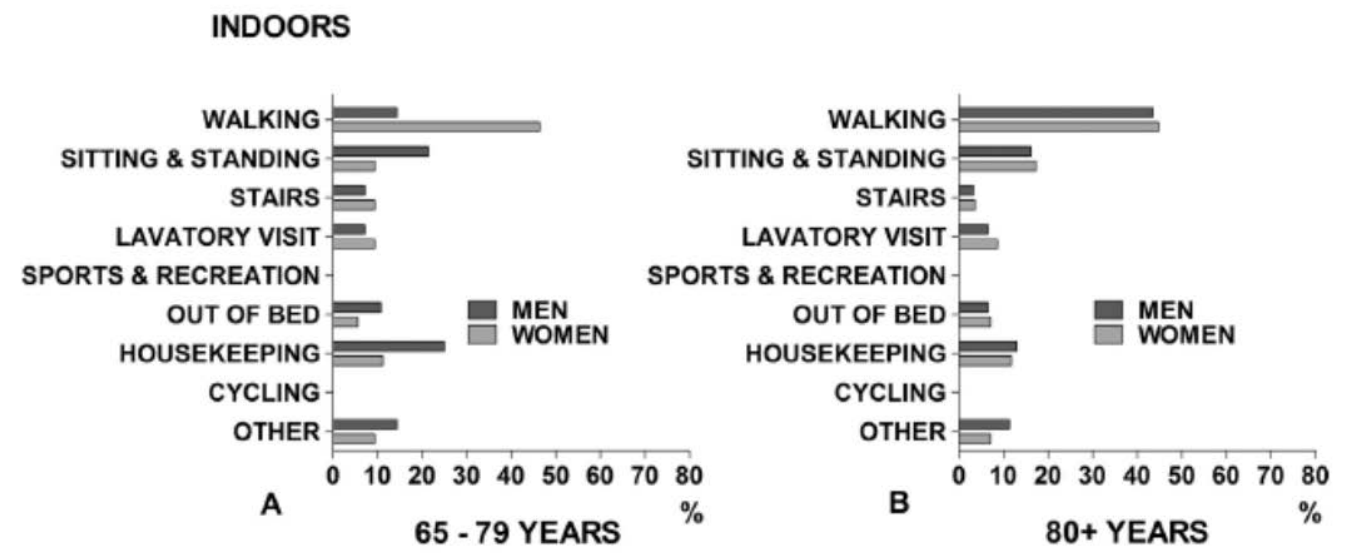

\section{OUTDOORS}
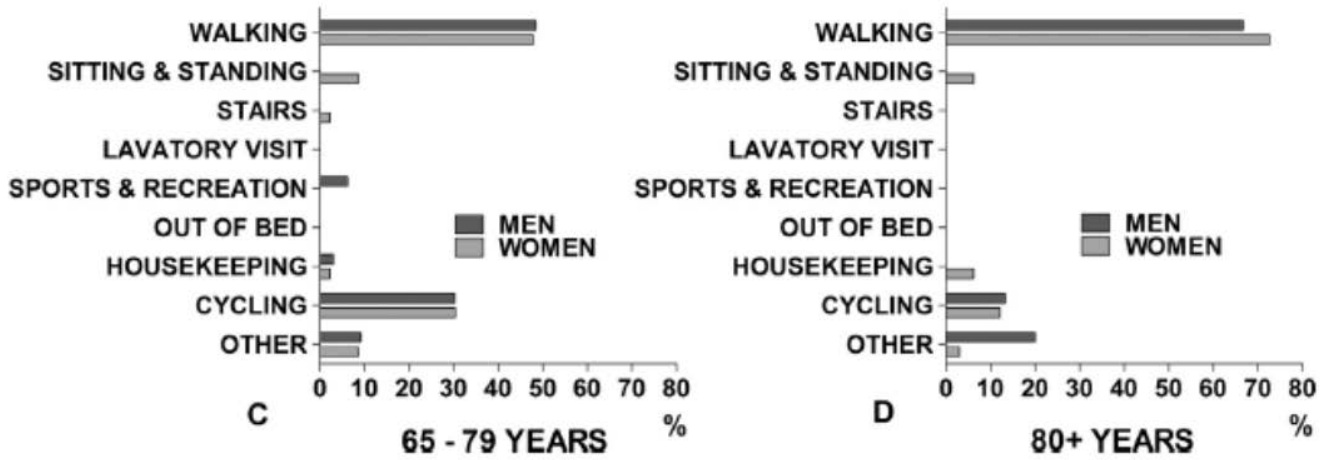

Fig. 3. Circumstances surrounding falls leading to a hip fracture, stratified by age and gender. Indoor (A and B) and outdoor (C and D) activities leading to a hip fracture, stratified by the age categories 65-79 years ( $A$ and $C$ ) and $80+$ years ( $B$ and $D)$. Data are shown in percentages. 


\section{SUPPLEMENTARY}

Figure X. Circumstances surrounding all falls, stratified by location and season.

Activities leading to a fall stratified by the seasons, winter (A), spring (B), summer (C), autumn (D), and location (indoor and outdoor). Data are shown in percentages.

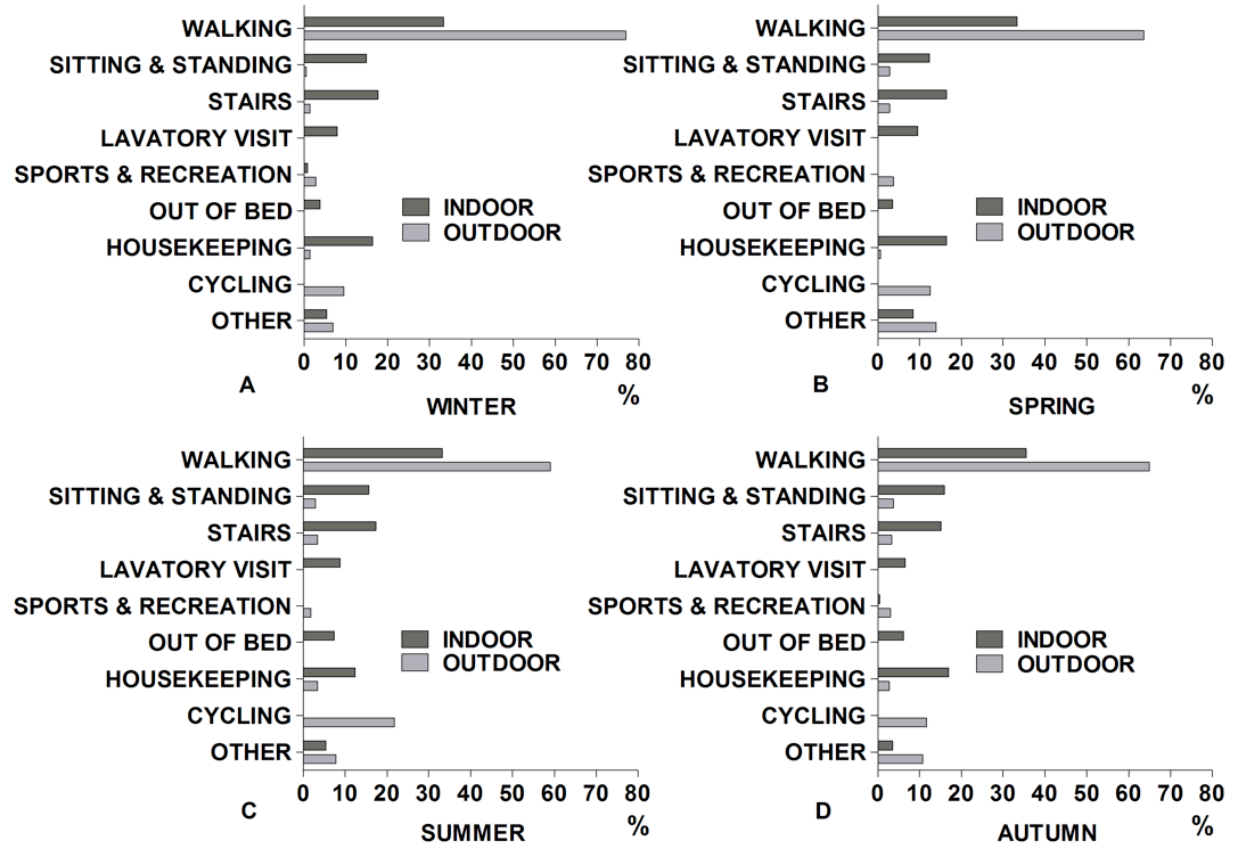

